\section{Development and validation of an algorithm using health administrative data to define patient attachment to primary care providers}

\author{
Liisa Jaakkimainen, Imaan Bayoumi, Richard H. Glazier, Kamila Premji, \\ Tara Kiran, Shahriar Khan, Eliot Frymire and Michael E. Green \\ (Information about the authors can be found at the end of this article.)
}

Patient attachment to PCPs

\begin{abstract}
Purpose - The authors developed and validated an algorithm using health administrative data to identify patients who are attached or uncertainly attached to a primary care provider $(\mathrm{PCP})$ using patient responses to a survey conducted in Ontario, Canada.

Design/methodology/approach - The authors conducted a validation study using as a reference standard respondents to a community-based survey who indicated they did or did not have a PCP. The authors developed and tested health administrative algorithms against this reference standard. The authors calculated the sensitivity, specificity positive predictive value (PPV) and negative predictive value (NPV) on the final patient attachment algorithm. The authors then applied the attachment algorithm to the 2017 Ontario population.

Findings - The patient attachment algorithm had an excellent sensitivity $(90.5 \%)$ and PPV (96.8\%), though modest specificity $(46.1 \%)$ and a low NPV $(21.3 \%)$. This means that the algorithm assigned survey respondents as being attached to a PCP and when in fact they said they had a PCP, yet a significant proportion of those found to be uncertainly attached had indicated they did have a PCP. In 2017, most people in Ontario, Canada $(85.4 \%)$ were attached to a PCP but $14.6 \%$ were uncertainly attached.

Research limitations/implications - Administrative data for nurse practitioner's encounters and other interprofessional care providers are not currently available. The authors also cannot separately identify primary care visits conducted in walk in clinics using our health administrative data. Finally, the definition of hospital-based healthcare use did not include outpatient specialty care.

Practical implications - Uncertain attachment to a primary health care provider is a recurrent problem that results in inequitable access in health services delivery. Providing annual reports on uncertainly attached
\end{abstract}

(C) Liisa Jaakkimainen, Imaan Bayoumi, Richard H. Glazier, Kamila Premji, Tara Kiran, Shahriar Khan, Eliot Frymire and Michael E. Green. Published by Emerald Publishing Limited. This article is published under the Creative Commons Attribution (CC BY 4.0) licence. Anyone may reproduce, distribute, translate and create derivative works of this article (for both commercial and non-commercial purposes), subject to full attribution to the original publication and authors. The full terms of this licence may be seen at http://creativecommons.org/licences/by/4.0/legalcode

This study was supported by the Innovations Strengthening Primary Health Care through Research (INSPIRE PHC) program, which was funded through the Ontario Ministry of Health and Long-Term Care (MOHLTC). This study was also supported by ICES, which is funded by an annual grant from the MOHLTC. Parts of this material are based on data and information compiled and provided by the MOHLTC and CIHI. The analyses, conclusions, opinions and statements expressed herein are solely those of the authors and do not reflect those of the funding or data sources; no endorsement is intended or should be inferred. Richard Glazier reported receiving grants from CIHR, Ontario SPOR Support Unit and St Michael's Hospital Foundation during the conduct of the study; receiving personal fees from ICES, St Michael's Hospital and University of Toronto and is receiving a portion of income paid by CIHR to ICES. Tara Kiran is supported by the Fidani Chair in Improvement and Innovation at the University of Toronto and by the Canadian Institutes of Health Research and Health Quality Ontario as an embedded clinician researcher. Michael Green is supported by the Brian Hennen Chair in Family Medicine at Queen's University.

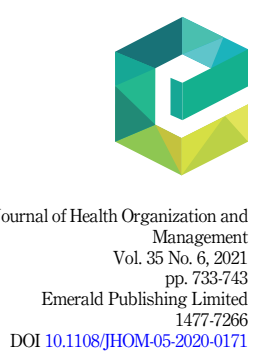


JHOM 35,6

\section{4}

patients can help evaluate primary care system changes developed to improve access. This algorithm can be used by health care planners and policy makers to examine the geographic variability and time trends of the uncertainly attached population to inform the development of programs to improve primary care access.

Social implications - As primary care is an essential component of a person's medical home, identifying regions or high need populations that have higher levels of uncertainly attached patients will help target programs to support their primary care access and needs. Furthermore, this approach will be useful in future research to determine the health impacts of uncertain attachment to primary care, especially in view of a growing body of the literature highlighting the importance of primary care continuity.

Originality/value - This patient attachment algorithm is the first to use existing health administrative data validated with responses from a patient survey. Using patient surveys alone to assess attachment levels is expensive and time consuming to complete. They can also be subject to poor response rates and recall bias. Utilizing existing health administrative data provides more accurate, timely estimates of patient attachment for everyone in the population.

Keywords Primary care, Health services research, Methodology, Big data

Paper type Research paper

\section{Introduction}

Access to primary care is the foundation of a high functioning health care system (Starfield et al., 2005). Lack of attachment to primary care is associated with multiple patient level and health system level problems. Unattached patients experience lower quality of care, higher inpatient hospitalization and readmission rates and higher ER utilization (Olsen et al., 2017; Shea et al., 1992a, b; Shi et al., 1999; Ramondetta et al., 2015; Ohle et al., 2017; Farion et al., 2015; Estrada and Ownby, 2017). Having a regular primary care provider (PCP) has also been linked with better patient experiences including greater trust and confidence in care and more personalized care (von Bultzingslowen et al., 2006). In Canada, many provinces have identified the critical need for attachment to a PCP and a variety of approaches to address have been implemented (Breton et al., 2017). It is critical for health system planners to efficiently assess numbers, locations and profiles of unattached patients to enable dataguided health human resource and program planning.

Multiple researchers have identified valid approaches for identifying physician patient profiles in administrative data, (Lasko et al., 2006; Katz et al., 2004) but these methods do not necessarily identify unattached patients. Provost et al. (2015) developed an algorithm to identify unattached patients in administrative data, but were unable to validate their approach with patient survey data. We sought to develop and validate an algorithm using health administrative data to identify patients who are attached to consistent PCP using patient responses to the Health Care Experiences Survey (HCES) in Ontario, Canada.

\section{Objectives}

The objectives for this study were to develop and validate a patient attachment algorithm for persons over 16 years of age using health administrative data and to apply this algorithm to the entire population of Ontario, Canada.

\section{Methods}

Study method: We conducted a validation study of respondents to the HCES conducted by the Ontario Ministry of Health (n.d.). The HCES is a voluntary, telephone survey conducted quarterly. We used survey data between October 2012 to September 2018 and included Ontario residents aged 16 years of age and older. The sampling frame was weighted to geographic regions in Ontario called Local Health Integration Networks (LHINs) and oversampled rural areas.

Reference standard: Our reference standard included the HCES respondents who indicated they did or did not have a PCP. We compared the responses from HCES 
respondents to their actual health care use of PCPs by examining Ontario health administrative data. For this study, primary care use meant being enrolled with a family physicians' (FPs') practice (rostered) or visiting a FP.

Study cohort: The study cohort included respondents to the HCES who consented to have their questionnaires linked to the Ontario health administrative data held at ICES. ICES is an independent, non-profit research institute whose legal status under Ontario's health information privacy law allows it to collect and analyze health care and demographic data, without consent, for health system evaluation and improvement (ICES, n.d.). The vast majority $(92 \%)$ of the HCES respondents were linked to the Ontario health administrative data (Ontario Ministry of Health, n.d.).

Health administrative data: Several sources of health administrative data were used to identify primary care use. In Ontario, and elsewhere in Canada, FPs are the physician providers of primary care for adults and most children (Jaakkimainen et al., 2006). The Client Agency Program Enrollment (CAPE) database was used to identify patients who were enrolled with a FP belonging to a primary care patient enrollment model (PEM) in Ontario (McLeod et al., 2016). There are several types of PEMs in Ontario which formally enroll (roster) patients to a FP, including those remunerated through blended capitation (age- and sex-adjusted monthly payments for each enrolled patient plus a small proportion of fee-forservice payments) and those primarily paid by fee-for-service. A community health centre (CHC) database identified patients visiting a CHC, where FPs are salaried and funded under a global budget. Finally, the Ontario Health Insurance Plan (OHIP) database contains fee-forservice physician claims for all physicians in Ontario. For this study, primary care core visits refer to a list of services determined to be part of a comprehensive primary care practice (Schultz and Glazier, 2017). Hospital-based healthcare use referred to any emergency department (ED) visit or hospitalizations. ED visits came from the Canadian Institute for Health Information (CIHI) National Ambulatory Record System (NACRS) database and hospital admissions came from the CIHI Discharge Abstract Database (DAD). We included all acuity (Canadian Triage and Acuity Scale (CTAS)) levels of ED visits (Fernandes et al., 2013). These datasets were linked using unique encoded identifiers and analyzed at ICES.

Patient characteristics: Patient age and sex were determined from the Ontario provincial health registry called the Registered Persons Database (RPDB). Neighborhood income quintile was derived by linking postal code to census dissemination area (Statistics Canada, 2013). Rurality was determined by linking postal code with the Rurality Index of Ontario (Kralj, 2000).

Patient attachment algorithm using health administrative data: We developed hierarchical steps in attributing a HCES respondent as being attached to a PCP with the order being set by those steps that attached the largest numbers of patients. Under the Canada Health Act, all residents in each province are entitled to publicly funded healthcare services (Marchildona and Hutchison, 2016). Consequently, all provinces in Canada collect physicians' claims data. Primary care reform in Ontario started in 2002 and saw a large increase in FPs participating in formal primary care patient enrollment (roster) models (PEMs) (Marilisa Tiedemann, 2020). However, formal primary care PEMs are not available in all Canadian provinces. We developed a patient attachment algorithm which includes steps using PEMs if they are available in a jurisdiction. However, if not available, then physician claims data can be used.

First, HCES respondents found to be enrolled in a PEM were considered as having a PCP. Enrollment is the system requirement in establishing a connection to a PCP and is the health system indicator of attachment. Second, HCES respondents seen at a $\mathrm{CHC}$ were considered as having a PCP. Third, we defined HCES respondents as being "virtually" enrolled to a PCP with whom the plurality of their primary care core visits were made over a two-year period. All OHIP PCP claims by HCES respondents were extracted with only one claim per patient 
$\mathrm{JHOM}$ 35,6

736

per PCP physician per day being counted. Total primary care core visits to each individual PCP and total primary care core visits per patient were counted. However, we did not want to virtually enroll a HCES respondent to a PCP whom themselves may have low continuity of care $(\mathrm{CoC})$ with their patients, such as walk-in clinic PCPs. Therefore, we calculated a PCP $\mathrm{CoC}$ index which is a visit-based measure of the proportion of an individual PCP visits over all physician's visits seen over a two-year time period (Jee and Cabana, 2006). The PCP CoC index was determined with a numerator of patients virtually rostered to a PCP divided by the denominator of all unique patients the same PCP had seen over two years. If the PCP CoC was less than or equal to $10 \%$, then this PCP had a low PCP CoC and HCES respondents virtually enrolled to these PCPs were then deemed to be uncertainly attached. Therefore, patients were deemed attached to a PCP if they belonged to a PEM, were seen in a $\mathrm{CHC}$ or they were virtually enrolled to a PCP who had a PCP CoC index over $10 \%$. Otherwise, patients were deemed uncertainly attached. We used the term uncertainly attached as opposed to unattached because patients could and in fact did still access PCPs (for example episodic care in walk in clinics), even when they said they did not have access to ongoing primary care.

Validation analyses: We conducted several analyses to assess the impact of assumptions made in developing the patient attachment algorithm. We split the study cohort into a development dataset and a validation dataset. The development dataset consisted of all HCES respondents linked with ICES data and surveyed between October 2012 and September 2017 $(N=39,285)$ and the validation dataset consisted of HCES respondents linked with ICES surveyed between October 2017 and September $2018(N=6,621)$. The HCES responses to the question of whether they had or did not have a PCP were compared to each step of the patient attachment algorithm (described above). In addition, the third step of the patient attachment algorithm whereby HCES respondents were virtually enrolled to a PCP were examined by comparing a cut-point for PCP CoC index of less than $25 \%$. Finally, we examined whether the remaining uncertainly attached patients had any primary care core visits or any hospitalbased healthcare use in the two years prior to their completing the HCES survey.

Statistical analysis: The sensitivity, specificity, positive predictive value (PPV) and negative predictive value (NPV) were calculated for the overall patient attachment algorithm. For the validation analyses two-sample $t$-tests were undertaken to compare proportions between groups, with $p<0.001$ indicating statistical significance. All analyses were performed using SAS Enterprise Guide version 7.1 (Cary, NC) (SAS, n.d.).

Application of the Patient Attachment Algorithm to the Ontario population: The patient attachment algorithm was applied to the 2017 population of Ontario. The 2017 Ontario population included all residents with a valid health care number and who were alive as of December 31, 2017. As the HCES survey is conducted for resident ages 16 years and older, our patient attachment algorithm was developed for people over 16 years of age. However, for the application of our algorithm to the entire Ontario population in 2017, we added another step where we applied a health administrative data pediatric access algorithm for children under 19 years of age. This algorithm has been previously validated for pediatric health services research to examine primary care access in pediatric populations (Guttmann et al., 2010). If children under 19 years of age were not attached to a PCP after applying our three patient attachment algorithm steps (which were validated against HCES respondents aged 16 years and older), we then assigned them to a PCP based on the pediatric access algorithm.

The use of data in this project was authorized under section 45 of Ontario's Personal Health Information Protection Act, which does not require review by a Research Ethics Board.

\section{Results}

Overall, 55,392 HCES respondents were linked to the Ontario health administrative data between 2012 and 2018, of which 52,504 (94.8\%) indicated they had a PCP and 2,888 (5.2\%) 
indicated they did not. Table 1 presents the demographic characteristics of the HCES respondents. A significantly higher proportion of HCES respondents attached to PCP were older, female, lived in urban areas and in higher income neighborhoods than HCES respondents uncertainly attached to PCP.

A flowchart of the HCES respondent attachment algorithm using health administrative data is provided in Figure 1. 81.4\% of HCES respondents were rostered to a PEM and 1.5\% were seen in a CHC. Of the $9486 \mathrm{HCES}$ respondents not rostered to a PEM or seen in a CHC, $3,180(33.5 \%)$ were virtually rostered to a $\mathrm{PCP}$ with greater than or equal to $10 \% \mathrm{FP} \mathrm{CoC}$ index. Overall, $88.6 \%$ of HCES respondents were defined as being attached to a PCP or group using health administrative data. The remaining 6,306 (11.4\%) of HCES respondents were deemed uncertainly attached.

The validation analyses found no statistically significant differences between the development dataset and the validation dataset in any step of the patient attachment algorithm. Using a PCP CoC index cut point of less than $10 \%$ had a higher proportion of HCES respondents reporting they had no PCP and being attributed to the uncertainly attached group (true negative) when compared to a less than $25 \%$ cut point. There was no difference in the proportion of HCES respondents attributed to the attached group using either PCP CoC index cut point of less than $10 \%$ or $25 \%$ and reporting they had a PCP (true positive).

Amongst the 6306 HCES patients who remained uncertainly attached using the algorithm, $4,416(70 \%)$ had at least one core primary care visits in the two years prior to their completing the HCES survey. For the subgroup of HCES respondents uncertainly attached and saying

\begin{tabular}{|c|c|c|c|c|c|}
\hline & Attached & $\begin{array}{l}\text { Uncertainly } \\
\text { attached }\end{array}$ & Total & $\begin{array}{c}\text { Ontario population } \geq 16 \text { years } \\
\text { of age }\end{array}$ & \\
\hline Age (Mean \pm SD) & $52.99 \pm 17.29$ & $49.83 \pm 17.54$ & $52.63 \pm 17.35$ & $47.55 \pm 18.84$ & \\
\hline $\begin{array}{l}\text { Age Groups } \\
16-18 \\
19-34 \\
35-49 \\
50-64 \\
65-74 \\
75-84 \\
85+\end{array}$ & $\begin{array}{c}1,079(2.2 \%) \\
7,109(14.5 \%)^{*} \\
12,194(24.8 \%) \\
14,842(30.2 \%) \\
8,422(17.2 \%)^{*} \\
4,317(8.8 \%)^{*} \\
1,123(2.3 \%)^{*}\end{array}$ & $\begin{array}{c}202(3.2 \%) \\
1,222(19.4 \%) \\
1,618(25.7 \%) \\
1,880(29.8 \%) \\
851(13.5 \%) \\
422(6.7 \%) \\
111(1.8 \%)\end{array}$ & $\begin{array}{c}1,281(2.3 \%) \\
8,331(15.0 \%) \\
13,812(24.9 \%) \\
16,722(30.2 \%) \\
9,273(16.7 \%) \\
4,739(8.6 \%) \\
1,234(2.2 \%)\end{array}$ & $\begin{array}{c}475,431(4.1 \%) \\
2,953,638(25.4 \%) \\
2,826,277(24.3 \%) \\
2,996,962(25.8 \%) \\
1,329,508(11.5 \%) \\
710,156(6.1 \%) \\
318,551(2.7 \%)\end{array}$ & \\
\hline $\begin{array}{l}\text { Sex } \\
\text { Female } \\
\text { Male }\end{array}$ & $\begin{array}{l}28,469(58.0 \%)^{*} \\
20,617(42.0 \%)^{*}\end{array}$ & $\begin{array}{l}3,143(49.8 \%) \\
3,163(50.2 \%)\end{array}$ & $\begin{array}{l}31,612(57.1 \%) \\
23,780(42.9 \%)\end{array}$ & $\begin{array}{l}5,971,110(51.4 \%) \\
5,639,413(48.6 \%)\end{array}$ & \\
\hline $\begin{array}{l}\text { Rurality } \\
\text { Urban } \\
\text { Semi-urban } \\
\text { Rural } \\
\text { Missing }\end{array}$ & $\begin{array}{c}29,947(61.0 \%)^{*} \\
12,575(25.6 \%)^{*} \\
5,859(11.9 \%)^{*} \\
705(1.4 \%)^{*}\end{array}$ & $\begin{array}{c}3,087(49.0 \%) \\
2,064(32.7 \%) \\
843(13.4 \%) \\
312(4.9 \%)\end{array}$ & $\begin{array}{c}33,034(59.6 \%) \\
14,639(26.4 \%) \\
6,702(12.1 \%) \\
1,017(1.8 \%)\end{array}$ & $\begin{array}{c}8,451,253(72.8 \%) \\
2,224,266(19.2 \%) \\
839,468(7.2 \%) \\
95,536(0.8 \%)\end{array}$ & \\
\hline $\begin{array}{l}\text { Income Quintiles } \\
1 \text { Low } \\
2 \\
3 \\
4 \\
5 \text { High } \\
\text { Missing } \\
\text { Note(s): } * p<0.0\end{array}$ & $\begin{array}{c}8,030(16.4 \%)^{*} \\
9,245(18.8 \%) \\
9,732(19.8 \%) \\
10,873(22.2 \%)^{*} \\
11,021(22.5 \%)^{*} \\
185(0.4 \%)\end{array}$ & $\begin{array}{c}1,293(20.5 \%) \\
1,213(19.2 \%) \\
1,216(19.3 \%) \\
1,265(20.1 \%) \\
1,275(20.2 \%) \\
44(0.7 \%)\end{array}$ & $\begin{array}{c}9,323(16.8 \%) \\
10,458(18.9 \%) \\
10,948(19.8 \%) \\
12,138(21.9 \%) \\
12,296(22.2 \%) \\
229(0.4 \%)\end{array}$ & $\begin{array}{r}2,112,944(18.2 \%) \\
2,237,908(19.3 \%) \\
2,320,365(20.0 \%) \\
2,509,732(21.6 \%) \\
2,380,346(20.5 \%) \\
49,228(0.47 \%)\end{array}$ & $\begin{array}{r}\text { Table 1. } \\
\text { Demographic } \\
\text { characteristics of the } \\
\text { attached and } \\
\text { uncertainly attached } \\
\text { HCES respondents }\end{array}$ \\
\hline
\end{tabular}




\section{JHOM} 35,6

\section{8}

Figure 1.

Flowchart of the steps for the patient attachment algorithm validation

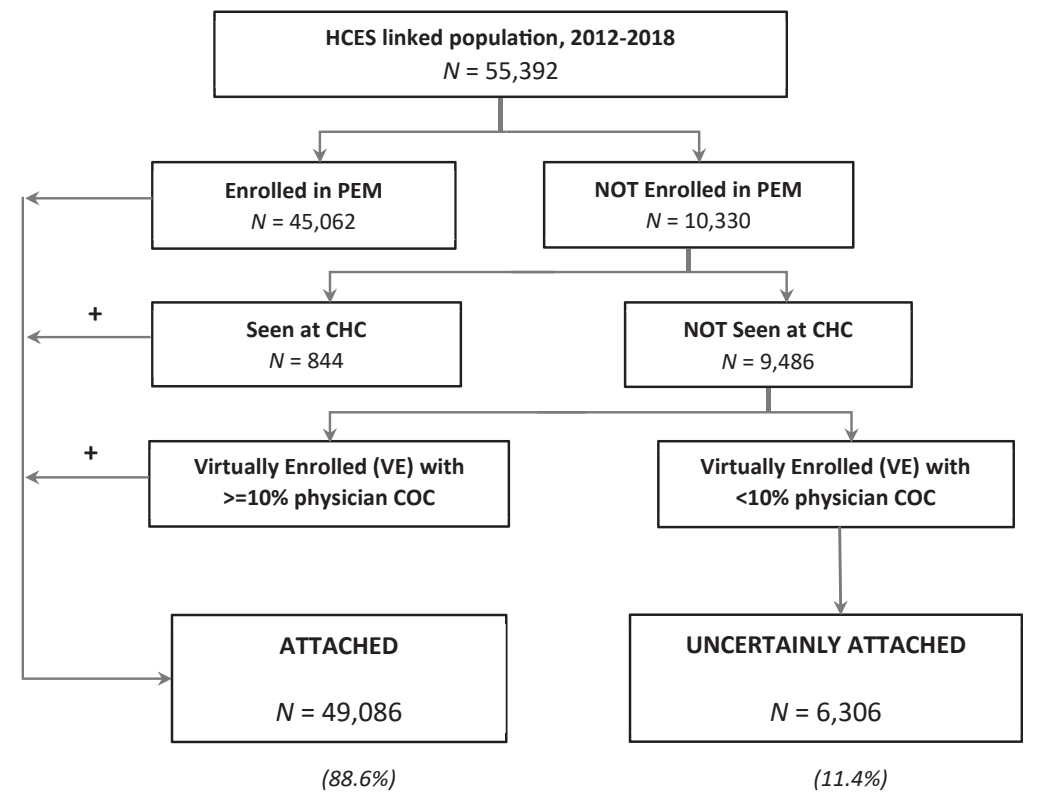

they did not have a PCP, we found 225/692 (32.5\%) did use health care services (hospitalbased healthcare use) in the two year prior to their completing the survey. For HCES respondents with a child less than 16 years of age, $94.2 \%$ indicated their child had a FP or pediatrician.

The patient attachment algorithm for adults over 16 years of age had a sensitivity of $90.5 \%$, specificity of $46.1 \%$, a PPV of $96.8 \%$ and a NPV of $21.3 \%$ (see Table 2 ). In other words, our patient attachment algorithm identified $90.5 \%$ of HCES respondents who said they had a PCP, as being attached to a PCP. However, our algorithm identified $46.1 \%$ of HCES respondents who said they did not have a PCP as being uncertainly attached to a PCP.

The patient attachment algorithms and the pediatric access algorithms were applied to the 2017 Ontario population (Figure 2), 88.4\% of the Ontario population were attached, and $11.6 \%$ were uncertainly attached to a PCP.

\section{Discussion}

In 2017, most people in Ontario, Canada (88.4\%) were attached to a PCP but $11.6 \%$ were uncertainly attached. The patient attachment algorithm had an excellent true positive rate

\begin{tabular}{|c|c|c|c|}
\hline & $\begin{array}{l}\text { HCES respondents } \\
\text { indicating they did a } \\
\text { primary care provider }\end{array}$ & $\begin{array}{c}\text { HCES respondents indicating } \\
\text { they did not have a primary } \\
\text { care provider }\end{array}$ & \\
\hline \multirow{4}{*}{$\begin{array}{l}\text { Algorithm Identified as being } \\
\text { ATTACHED to a primary care } \\
\text { provider } \\
\text { Algorithm Identified as being } \\
\text { UNCERTAINLY ATTACHED to a } \\
\text { primary care provider }\end{array}$} & 47,516 & 1,570 & 49,086 \\
\hline & & & \\
\hline & 4,963 & 1,343 & 6,306 \\
\hline & 52,479 & 2,913 & 55,392 \\
\hline
\end{tabular}

Table 2.

$2 \times 2$ Table of the Patient Attachment Algorithm again HCES respondents $(N=55,392)$ 


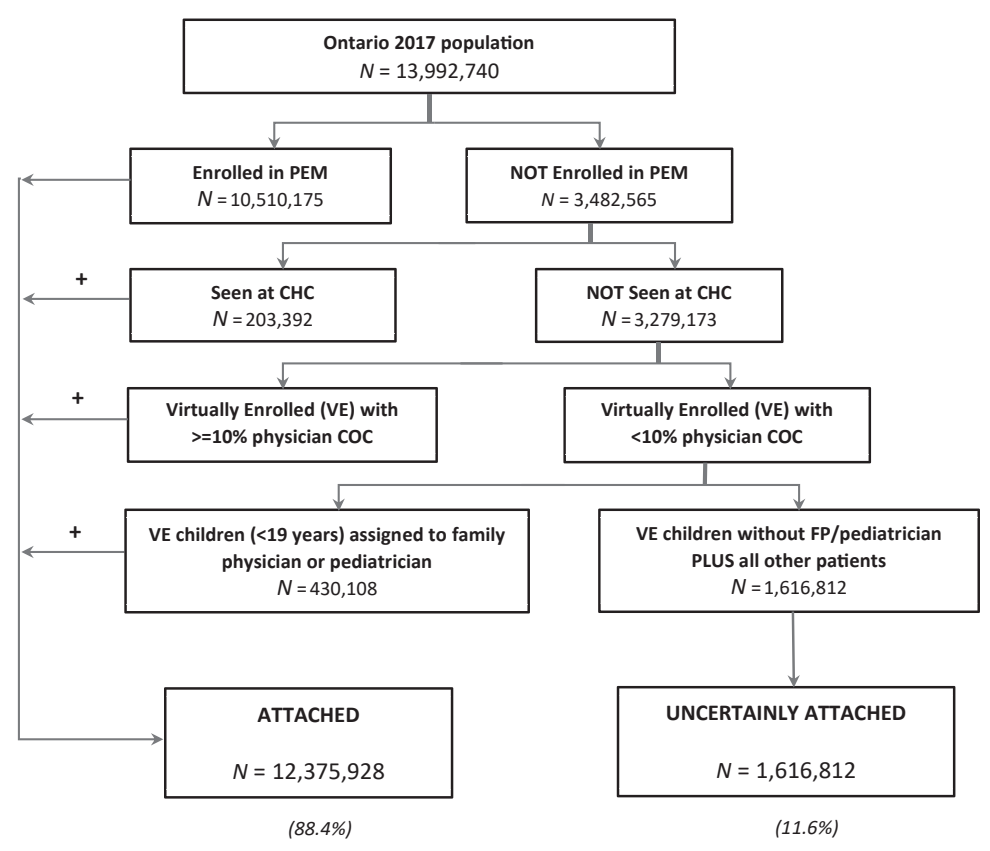

\section{Patient attachment to PCPs}

739

Figure 2. Flowchart of the patient attachment algorithm applied on the ontario 2017 population

(sensitivity and PPV) meaning the algorithm identified HCES respondents as being attached to a PCP when HCES respondents themselves indicated they have a PCP. But our algorithm had a modest specificity (true negative rate) and a low NPV. This means that while the algorithm identified HCES respondents as being uncertainly attached does not necessarily indicate that they did not have access to a PCP. Some people may feel healthy and may not feel the need to seek medical care. Others may visit walk-in clinics on a needed basis and may not feel they need to see the same PCP. Indeed we found one-third of HCES respondents who were uncertainly attached to a PCP and indicated they did not have a PCP, did use health care services in the two years prior to their completing the survey.

Our study was able to link the responses from individuals about their primary care attachment with their actual use of the primary care system. Previous work conducted in Ontario in 2007 and 2008 had used a patient survey alone to estimate $92.9 \%$ (95\% CI: 92.4, 93.4) of people over 16 years of age were attached to a PCP (Hay et al., 2010). The HCES similarly found $94.8 \%$ of respondents saying they had a PCP. Patient surveys are expensive and time consuming to complete. They can also be subject to sampling bias including poor response rates, recall bias and not capturing those without a phone. Utilizing existing health administrative data can provide more accurate, timely estimates of patient attachment for everyone in the population.

In Canada, medically necessary physician visits are universally provided to residents and paid and managed by provincial government health plans (Government of Canada, n.d.). The Ontario primary care system includes both formal (patient rostered) and informal enrolment models of care. Our attachment algorithm incorporates both types of enrolment methods. For jurisdictions that do not have a formal enrolment system or rostering of patients to PCP, they could still use our algorithm by applying our "virtual enrollment" method of attaching patients based on their visit patterns to a PCP. Similarly, primary care systems that are mainly based on formal enrolment methods can also use our algorithm. In Ontario patients 
$\mathrm{JHOM}$ 35,6

are enrolled (rostered) to an individual PCP and not to a practice. Most PCPs that enroll patients, practice in a group primary care practice setting with other PCPs who enroll patients (Glazier et al., 2012). PCPs may work in other clinical settings such as EDs or nursing homes. In our algorithm, patients seen in these settings would not be attributed to the PCP as these encounter claim codes are specific to EDs or nursing home locations. Our algorithm will attach patients to individual PCPs, though the reality is most PCPs work in a group setting.

Information about people uncertainly attached to a PCP is needed by health care planners, decisions makers and policy makers. As primary care is an essential component of a person's medical home, identifying regions or high need populations that have higher levels of uncertainly attached patients will help target programs to support their primary care access and needs. Providing annual reports on uncertainly attached patients can also help evaluate primary care system changes developed to improve access. Furthermore, this approach will be useful in future research to determine the health impacts of uncertain attachment to primary care, especially in view of a growing body of literature highlighting the importance of primary care continuity.

There are limitations to our study. We only looked at FPs as the providers of primary care and we did not include nurse practitioners. For those patients in primary care teams we also did not look at care provided by interprofessional healthcare providers (e.g. pharmacists, social work). Nurse practitioner-led clinics (NPLC) are more common in rural and underserviced communities and in other provinces and there are currently 27 NPLCs in Ontario (Nurse Practitioner Association of Ontario, n.d.; College of Nurse of Ontar, 2017). Unfortunately, administrative data for nurse practitioner's encounters and other interprofessional care providers are not currently available. Health administrative data should strive to include encounter data from all primary health care providers as this can help monitor and evaluate the full picture of primary healthcare delivery. We also cannot separately identify primary care visits conducted in walk in clinics using our health administrative data. In addition, our definition of hospital-based healthcare use did not include outpatient specialty care. And finally, the HCES respondent sample is not generalizable to the entire Ontario population. The survey did oversample people living in rural communities and people who do not have a phone or are not able to provide answers over the phone were not included.

\section{Conclusions}

We developed a patient attachment algorithm using existing health administrative data compared to responses from a population-based patient survey. This algorithm had an excellent sensitivity and PPV, though a modest specificity. It can be used by health care planners and policy makers to examine the geographic variability and time trends of the uncertainly attached population to inform the development of programs to improve primary care access.

\section{References}

Breton, M., Green, M., Kreindler, S., Sutherland, J., Jbilou, J., Wong, S.T., Shaw, J., Crooks, V.A., Contandriopoulos, D., Smithman, M.A. and Brousselle, A.A. (2017), "A comparative analysis of centralized waiting lists for patients without a primary care provider implemented in six Canadian provinces: study protocol”, BMC Health Services Research, Vol. 17, p. 6, doi: 10.1186/ s12913-017-2007-8.

College of Nurse of Ontario (2017), "Membership statistics report 2017 pub. No. 43069 ISSN 1916 047X copyright (C college of nurses of Ontario", available at: http://www.cno.org/globalassets/ docs/general/43069_stats/2017-membership-statistics-report.pdf.

Estrada, R.D. and Ownby, D.R. (2017), "Rural asthma: current understanding of prevalence, patterns, and interventions for children and adolescents", Current Allergy and Asthma Reports, Vol. 17 No. 6, p. 37. 
Farion, K.J., Wright, M., Zemek, R., Neto, G., Karwowska, A., Tse, S., Reid, S., Jabbour, M., Poirier, S., Moreau, K.A. and Barrowman, N. (2015), "Understanding low-acuity visits to the pediatric emergency department”, Plos One [Electronic Resource], Vol. 10 No. 6, p. e0128927.

Fernandes, C.M., McLeod, S., Krause, J., Shah, A., Jewell, J., Smith, B. and Rollins, L. (2013), "Reliability of the Canadian Triage and Acuity Scale: interrater and intrarater agreement from a community and an academic emergency department”, CJEM, Vol. 15 No. 4, pp. 227-232, doi: 10. 2310/8000.2013.130943.

Glazier, R.H., Zagorski, B.M. and Rayner, J. (2012), Comparison of Primary Care Models in Ontario by Demographics, Case Mix and Emergency Department Use, 2008/09 to 2009/10 ICES Investigative Report, Institute for Clinical Evaluative Sciences, Toronto.

Government of Canada (n.d.), “Canada's health care system”, available at: https://www.canada.ca/en/ health-canada/services/health-care-system/reports-publications/health-care-system/canada.html.

Guttmann, A., Shipman, S.A., Lam, K., Goodman, D.C. and Stukel, T.A. (2010), "Primary care physician supply and children's health care use, access, and outcomes: findings from Canada", Pediatrics, Vol. 125 No. 6, pp. 1119-1126.

Hay, C., Pacey, M., Bains, N. and Ardal, S. (2010), "Understanding the unattached population in Ontario: evidence from the primary care access survey (PCAS)", Healthcare Policy = Politiques de sante, Vol. 6 No. 2, pp. 33-47.

ICES, Privacy at ICES (n.d.), Available at: https://www.ices.on.ca/Data-and-Privacy/Privacy-at-ICES (accessed 20 April 2020).

Jaakkimainen, L., Schultz, S.E., Klein-Geltink, J.E., Thiruchelvam, D. and Kopp, A. (2006), “Ambulatory physician care for adults and guttman A, schultz SE, Jaakkimainen L. Primary care for children”, in Jaakkimainen, L., Upshur, R., Klein-Geltink, J.E., Leong, A., Maaten, S., Schultz, S.E. and Wang, L. (Eds), Primary Care in Ontario: ICES Atlas, Institute for Clinical Evaluative Sciences, Toronto.

Jee, S.H. and Cabana, M.D. (2006), "Indices for continuity of care: a systematic review of the literature", Medical Care Research and Review, Vol. 63 No. 2, pp. 158-188, doi: 10.1177/ 1077558705285294.

Katz, A., De Coster, C., Bogdanovic, B., Soodeen, R.A. and Chateau, D. (2004), Using Administrative Data to Develop Indicators of Quality in Family Practice, Manitoba Centre for Health Policy, University of Manitoba, Winnipeg.

Kralj, B. (2000), "Measuring 'rurality' for purposes of health care planning: an empirical measure for Ontario", Ontario Medical Review, Vol. 67, pp. 33-5219.

Lasko, T.A., Atlas, S.J., Barry, M.J. and Chueh, H.C. (2006), “Automated identification of a physician's primary patients", Journal of the American Medical Informatics Association, Vol. 13 No. 1, pp. 74-79.

Marchildona, G.P. and Hutchison, B. (2016), "Primary care in Ontario, Canada: new proposals after 15 years of reform”, Health Policy, Vol. 120, pp. 732-738.

Marilisa Tiedemann (2020), Legal and Social Affairs Division. Parliament and Information Research Services. The Canada Health Act-An Overview (Background Paper), Publication No. 2019-54-E, Library of Parliament, Ottawa, (accessed 17 December 2019).

McLeod, L., Buckley, G. and Sweetman, A. (2016), "Ontario primary care models: a descriptive study", CMAJ Open, November, Vol. 114 No. 4, pp. E679-E688, doi: 10.9778/cmajo.20160069.

Nurse Practitioner Association of Ontario (n.d.), Available at: https://npao.org/about-npao/clinics/.

Ohle, R., Ohle, M. and Perry, J.J. (2017), "Factors associated with choosing the emergency department as the primary access point to health care: a Canadian population cross-sectional study", CJEM, Can., Vol. 19 No. 4, pp. 271-276.

Olsen, C.G., Boltri, J.M., Amerine, J. and Clasen, M.E. (2017), "Lacking a primary care physician is associated with increased suffering in patients with severe mental illness", Journal of Primary Prevention, Vol. 38 No. 6, pp. 583-596. 
JHOM 35,6

Ontario Ministry of Health (n.d.), "Ministry of long-term care", The Health Care Experience Survey, available at: http://www.health.gov.on.ca/en/common/healthcareexperiencesurvey.aspx (accessed 20 April 2020).

Provost, S., Perez, J., Pineault, R., Borges Da Silva, R. and Tousignant, P. (2015), "An algorithm using administrative data to identify patient Attachment to a family physician", International Journal of Family Medicine, Vol. 2015, p. 11, doi: 10.1155/2015/967230.

Ramondetta, L.M., Meyer, L.A., Schmeler, K.M., Daheri, M.E., Gallegos, J., Scheurer, M., Montealegre, J.R., Milbourne, A., Anderson, M.L. and Sun, C.C. (2015), "Avoidable tragedies: disparities in healthcare access among medically underserved women diagnosed with cervical cancer", Gynecologic Oncology, Vol. 139 No. 3, pp. 500-505.

SAS (n.d.), SAS Enterprise Guide Version 7.1, SAS Institute, Cary, NC.

Schultz, S.E. and Glazier, R.H. (2017), "Identification of physicians providing comprehensive primary care in Ontario: a retrospective analysis using linked administrative data", CMAJ Open, December, Vol. 195 No. 4, pp. E856-E863, doi: 10.9778/cmajo.20170083.

Shea, S., Misra, D., Ehrlich, M.H., Field, L. and Francis, C.K. (1992), "Predisposing factors for severe, uncontrolled hypertension in an inner-city minority population", New England Journal of Medicine, Vol. 327 No. 11, pp. 776-781.

Shea, S., Misra, D., Ehrlich, M.H., Field, L. and Francis, C.K. (1992), "Correlates of nonadherence to hypertension treatment in an inner-city minority population", American Journal of Public Health, Vol. 82 No. 12, pp. 1607-1612.

Shi, L., Samuels, M.E., Pease, M., Bailey, W.P. and Corley, E.H. (1999), "Patient characteristics associated with hospitalizations for ambulatory care sensitive conditions in South Carolina", Southern Medical Journal, Vol. 92 No. 10, pp. 989-998.

Starfield, B., Shi, L. and Macinko, J. (2005), "Contribution of primary care to health systems and health", The Milbank Quarterly, Vol. 83, pp. 457-502.

Statistics Canada (2013), Postal Code OM Conversion File (PCCF), Reference Guide, Statistics Canada, Ottawa.

von Bultzingslowen, I., Eliasson, G., Sarvimaki, A., Mattsson, B. and Hjortdahl, P. (2006), "Patients' views on interpersonal continuity in primary care: a sense of security based on four core foundations”, Family Practice, Vol. 23 No. 2, pp. 210-219.

\section{Author Affiliations}

Liisa Jaakkimainen, Primary Care and Health Systems, ICES, Toronto, Canada; Department of Family and Community Medicine and the Institute of Health Policy, Management and Evaluation, University of Toronto, Toronto, Canada and Department of Family and Community Medicine, Sunnybrook Health Sciences Centre, Toronto, Canada.

Imaan Bayoumi, Department of Familty Medicine, Queens University, Kingston, Canada.

Richard H. Glazier, ICES, Toronto, Canada; Department of Family and Community Medicine, St. Michael's Hospital, Toronto, Canada; Department of Family and Community Medicine, University of Toronto, Toronto, Canada and MAP Centre for Urban Health Solutions, St. Michael's Hospital, Toronto, Canada.

Kamila Premji, Central Ottawa Family Medicine Associates, Ottawa, Canada; Department of Family Medicine, University of Ottawa, Ottawa, Canada and Department of Family Medicine, Western University, London, Canada.

Tara Kiran, Department of Family and Community Medicine, St. Michaels's Hospital, University of Toronto, Toronto, Canada; MAP Centre for Urban Health Solutions, Li Ka Shing Knowledge Institute, St. Michael's Hospital, Toronto, Canada; Institute of Health Policy, Management and Evaluation, University of Toronto, Toronto, Canada and ICES, Toronto, Canada.

Shahriar Khan, ICES, Queens University, Kingston, Canada 
Eliot Frymire, ICES, Queens University, Kingston, Canada and Health Services and Policy Research Institute, Queen's University, Kingston, Canada.

Michael E. Green, Departments of Family Medicine, Health Services and Policy Research Institute, Kingston, Canada and ICES, Queens University, Kingston, Canada.

\section{Patient attachment to PCPs}

\section{About the authors}

Liisa Jaakkimainen is a Senior Core Scientist and Program Lead in Primary Care and Health Systems at ICES in Toronto, Ontario. She is a Funded Researcher and an Associate Professor in the Department of Family and Community Medicine and the Institute of Health Policy, Management and Evaluation at the University of Toronto, Toronto, Ontario. Dr. Jaakkimainen is also a Family Physician practising at the Sunnybrook Academic Family Health Team in Toronto, Ontario. Liisa Jaakkimainen is the corresponding author and can be contacted at: liisa.jaakkimainen@ices.on.ca

Imaan Bayoumi is a Family Physician and Clinician Researcher at the Department of Family Medicine, and Centre for Studies in Primary Care, Queens University. Kingston Ontario. Family Health Team, Kingston Ontario. She is also a Research Fellow at ICES in Kingston, Ontario.

Richard H. Glazier is a Senior Scientist in the Primary Care and Population Health Program at ICES in Toronto, Ontario. He is also a Clinician Scientist in the Department of Family and Community Medicine at the University of Toronto and at St. Michael's Hospital in Toronto, Ontario.

Kamila Premji is a Family Physician at Central Ottawa Family Medicine Associates in Ottawa, and an Assistant Professor and Junior Clinical Research Chair with the University of Ottawa's Department of Family Medicine. She is also a $\mathrm{PhD}$ candidate at Western University's Centre for Studies in Family Medicine.

Tara Kiran is the Fidani Chair for Improvement and Innovation and Vice Chair for Quality and Innovation in the Department of Family and Community Medicine, University of Toronto, Ontario. She is a Clinician Scientist in the Department of Family and Community Medicine at the University of Toronto and at St. Michael's Hospital in Toronto, a Scientist at MAP Centre for Urban Health Solutions at St. Michael's Hospital and an Adjunct Scientist at ICES.

Shahriar Khan is the lead analyst at ICES in Kingston, Ontario.

Eliot Frymire is a project manager in the Primary Care and Health Systems Program, ICES, in Kingston. He is also the research manager at the Health Services and Policy Research Institute, Queen's University in Kingston, Ontario.

Michael E. Green is the Brian Hennen Chair and head of the Department of Family Medicine, Faculty of Health Sciences, Queen's University, in Kingston, Ontario. He is also a senior adjunct scientist at ICES and is the clinical head at Kingston Health Providence Care Hospital.

For instructions on how to order reprints of this article, please visit our website:

www.emeraldgrouppublishing.com/licensing/reprints.htm

Or contact us for further details: permissions@emeraldinsight.com 